The acquired demyelinating polyneuropathies include acute (AIDP, Guillain-Barré syndrome, GBS) and chronic (CIDP, dysproteinemic) forms which differ primarily in their temporal profile. They are inflammatory-demyelinating diseases of the peripheral nervous system and likely have an immunologic pathogenesis. Although these neuropathies usually have a characteristic presentation, the electromyographer plays a central role in their recognition, since the demyelinating component of the neuropathy, which greatly reduces the differential diagnosis, is often first identified in the electromyography laboratory. In AIDP, the electromyographer, in addition to establishing the diagnosis, can sometimes predict the prognosis. Recognition of the chronic and dysproteinemic forms of acquired demyelinating polyneuropathy is important since they are treatable. The dysproteinemic forms also may be associated with occult systemic disorders that also may require treatment, independent of the neuropathy.

MUSCLE \& NERVE $\quad 12: 435-4511989$

\title{
ACQUIRED INFLAMMATORY DEMYELINATING POLYNEUROPATHIES: CLINICAL AND ELECTRODIAGNOSTIC FEATURES
}

JAMES W. ALBERS, MD, PhD, and JOHN J. KELLY, Jr, MD

Polyneuropathies are frequently difficult diagnostic problems, ${ }^{76}$ especially for clinicians who do not regularly deal with neuromuscular disorders or who lack adequate neuromuscular laboratory support. Increased diagnostic yield in polyneuropathies results from identification of the clinical and electrodiagnostic characteristics of demyelination. ${ }^{64}$ Some investigators ${ }^{28,46}$ have estimated that up to $25 \%$ of idiopathic neuropathics are autoimmune in nature, the majority being of the demyelinating type, including acute and chronic forms differing primarily in their temporal profile. Both are inflammatory-demyelinating diseases of peripheral nerves and nerve roots, although there may be extensive secondary axonal degener-

From the Neuromuscular Section of the Departments of Neurology and Physical Medicine and Rehabilitation, The University of Michigan. Ann Arbor, Michigan (Dr. Albers) and Department of Neurology. Tufts-New England Medical Center, Boston. Massachusetts (Dr. Kelly).

Acknowledgement: We thank Pamela Wilson for her skillful secretarial as. sistance in the preparation of this manuscript.

Presented in part at the American Association of Electromyography and Electrodiagnosis Tenth Arnual Continuing Education Course: Immuno logic Disorders of Peripheral Nerves, San Antonio, Texas, October 15 1987.

Address reprint requests to Dr. Albers at the Department of Neurology, The University of Michigan Medical Center, 1500 East Medical Center Drive, 1C325/0032. UH, Ann Arbor, Michigan, 48109 -0032.

Accepted for publication May 18, 1988.

$0148-639 \mathrm{X} / 1206 / 0435 \$ 04.00 / 17$

(c) 1989 John Wiley \& Sons, inc. ation. Specific etiologies have not been identified, but immunologic mechanisms almost certainly are involved. A major advance has been the recognition and understanding of demyelinating neuropathies associated with plasma cell dyscrasias. Although fewer in number, they are important because the circulating monoclonal protein itself likely damages nerve fibers. Understanding the mechanisms involved may help clarify the mechanisms of other obscure neuropathies, as well. The evaluation of patients with suspected acute inflammatory demyelinating polyneuropathy (AIDP, Guillain-Barré syndrome, GBS), or chronic inflammatory demyelinating polyneuropathy (CIDP) includes electrodiagnostic examination, such as that shown in Table 1. This examination is directed toward detecting evidence of segmental or multifocal demyelination.

\section{ACUTE INFLAMMATORY DEMYELINATING POLYNEUROPATHY}

Clinical Features. The incidence of AIDP is $0.5-$ 1.6/million/month, increasing slightly with advancing age until about 75 years, and diminishing thereafter. ${ }^{83}$ There are no known genetic or geographic predilections, although incidence is slightly higher for men than for women. ${ }^{68}$ Diagnostic criteria are descriptive and based upon recognition of a relatively characteristic clinical picture. ${ }^{6}$ Typical findings include rapidly progres- 
Table 1. Suspected inflammatory-demyelinating polyneuropathy: suggested electrodiagnostic protocol.

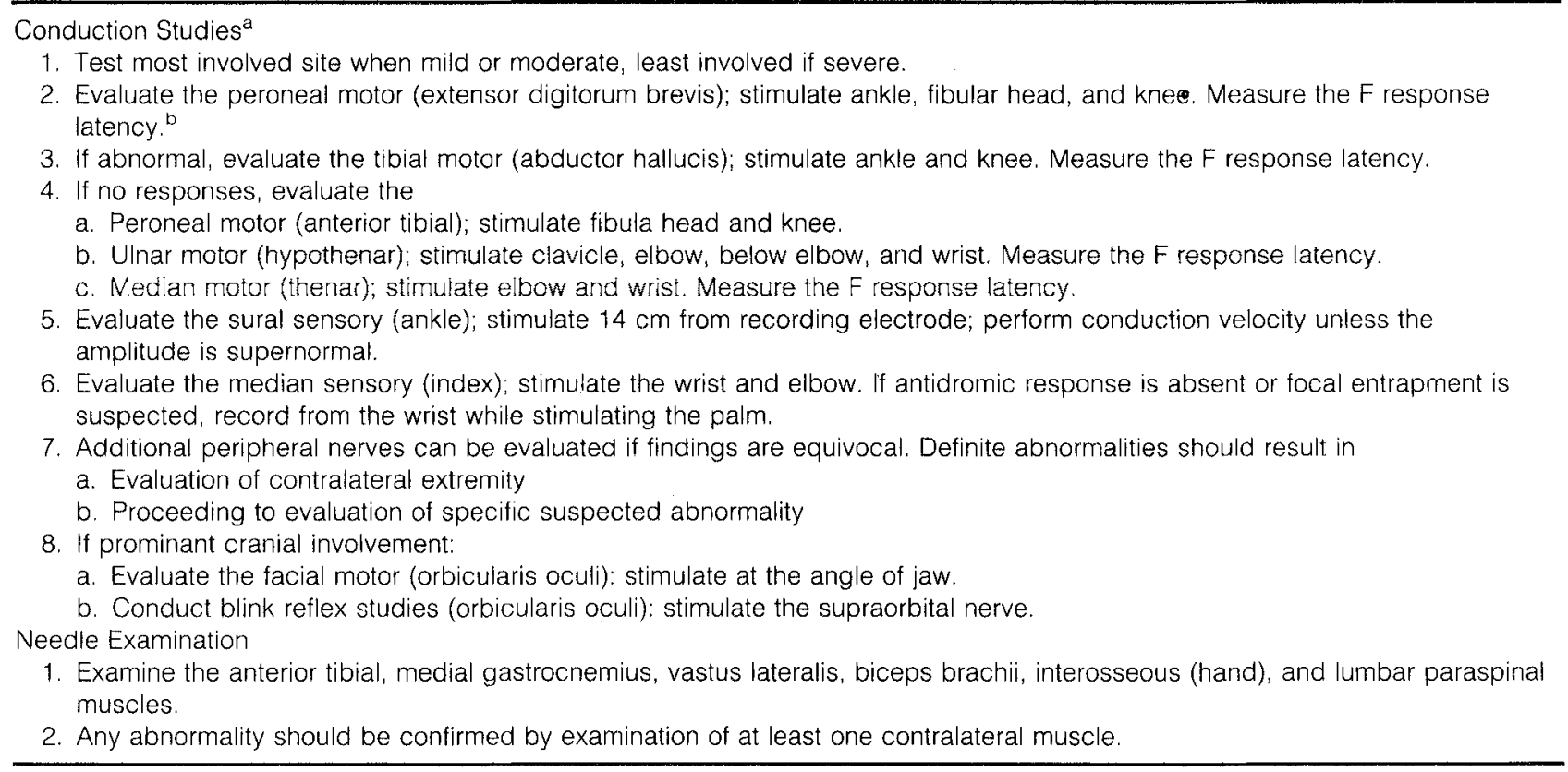

Source: Modified and reprinted from Ref. 2 with the permission of John Wiley \& Sons, Inc., Copyright (C) 1985.

a Words in parentheses indicate recording site for conduction studies.

${ }^{\circ}$ All F response latency measurements are for distal stimulation sites only.

sive weakness, often with bulbar and respiratory involvement; hyporeflexia or areflexia; slightly diminished sensation; autonomic dysfunction; and cerebrospinal fluid (CSF) protein elevation without pleocytosis. $5,7,48,68,88,96$

An antecedent event, most commonly a respiratory tract infection or gastroenteritis, is evident within 1 month (an average of 15 days) in over $60 \%$ of patients. ${ }^{4}$ Other antecedent events include other infections (e.g., hepatitis B, Epstein-Barr virus, cytomegalovirus, toxoplasmosis), immunization, ${ }^{83}$ malignant disease, and surgery. ${ }^{5}$ AIDP also has been associated with acquired HIVl infections, Lyme disease, Hodgkin's disease, and nonHodgkin's lymphoma. ${ }^{59}$

Initial manifestations include symmetrical motor and/or sensory symptoms. ${ }^{4}$ The most common complaint is leg weakness, ${ }^{5}$ and many patients demonstrate spread in a distal-to-proximal fashion. Prominent facial weakness occurs in about $50 \%$ of patients, ${ }^{5}$ and unilateral facial involvement has been described in up to $10 \%$ of patients, ${ }^{4}$ consistent with an isolated mononeuropathy superimposed on a generalized polyneuropathy. Other cranial nerve involvement leads to weakness of mastication, swallowing, and, rarely, eye movements. ${ }^{13}$ Despite common sensory symptoms, objective sensory loss is infrequent. ${ }^{13}$ When present, large myelinated fiber modalities (vibratory and joint position sensations) are involved. Back and extremity pain are frequent complaints during the early stages of the illness and may be severe.

Autonomic nervous system involvement includes bowel and bladder impairment, cardiac dysrhythmia, labile heart rate and blood pressure resulting in hypertension or hypotension, and impaired thermoregulation. ${ }^{5,93}$ The syndrome of inappropriate antidiuretic hormone secretion (SIADH) has been associated with AIDP, perhaps related to abnormalities of autonomic afferents arising from vascular stretch receptors. ${ }^{38,75}$

The Fisher syndrome is considered a variant of AIDP, consisting of ophthalmoplegia, ataxia, and areflexia. ${ }^{31}$ The temporal profile and CSF findings are indistinguishable from AIDP, and electrodiagnostic studies in some patients show a demyelinating polyneuropathy. ${ }^{35}$ Although some consider the syndrome a brainstem encephalitis, ${ }^{10}$ others ${ }^{80}$ propose peripheral explanations for all of the clinical signs.

The interval from the first neurologic symptom to peak impairment is less than 20 days in over $75 \%$ of patients, ${ }^{4}$ and $50 \%$ of patients reach their nadir by 2 weeks. ${ }^{13}$ Progression exceeding 4 weeks should be viewed cautiously and alternative diagnoses considered. Diaphragm and intercostal 
muscle involvement leads to respiratory paralysis in about $30 \%$ of patients. Mechanical ventilation usually is initiated between 6 and 18 days after onset (mean of 10 days). ${ }^{4}$ Initial improvement is observed within 40 days in over $80 \%$ of the patients, ${ }^{4}$ and the overall prognosis is quite good, with most patients demonstrating substantial clinical recovery within 6 months. ${ }^{4,59}$

The question of relapse in AIDP is difficult because of potential confusion with other disorders associated with relapsing polyneuropathy, including acute intermittent porphyria, ${ }^{3}$ systemic lupus erythematosus, and the chronic relapsing forms of inflammatory polyneuropathy. Distinct relapses in patients with otherwise typical AIDP do occur, although the rate is probably less than $5 \%$. In the multicentered, randomized trial of plasina exchange in the treatment of AIDP, ${ }^{90}$ four relapses were reported out of 254 patients during the study period.

Electrophysiologic Findings. A variety of electrodiagnostic findings has been reported, ${ }^{2,29,51,62,63,74,78,79}$ perhaps due to the temporal changes that occur in response to cumulative demyelination and axonal degeneration. The syndrome also may encompass patients with primary axonal degeneration as well as patients with severe distal conduction block resembling axonal degeneration. ${ }^{30,81}$ Nevertheless, the majority of patients demonstrate an evolving picture of a demyelinating polyneuropathy with superimposed axonal degeneration. ${ }^{2}$ A model of peripheral motor nerve, useful in predicting the electrophysiologic findings in multifocal demyelination, is de- scribed in the Appendix. Included is a discussion of the importance of abnormal temporal dispersion in distinguishing acquired from hereditary demyelinating polyneuropathies. ${ }^{54}$

Studies performed early in the course of AIDP, when the diagnosis may be unclear, often demonstrate only delayed or absent $F$ responses or $\mathrm{H}$ reflexes. Occasionally $\mathrm{F}$ responses appear normal but are difficult to elicit. During subsequent examinations, evidence of segmental conduction block and conduction slowing become apparent, with abnormal temporal dispersion of evoked responses, reduced conduction velocity, and prolonged distal latency. Identification of abnormal temporal dispersion and partial conduction block is the most reliable electrodiagnostic indicator of an acquired demyelinating polyneuropathy ${ }^{12}$ but not diagnostic of AIDP. ${ }^{1,23} \mathrm{~A}$ characteristic motor conduction recording from a patient with AIDP is shown in Fig. 1. The electrodiagnostic recognition of primary demyelination is imprecise and depends upon identifying abnormalities that cannot be explained by axonal involvement alone. This differentiation is most straightforward in acute disorders in previously well individuals without other sources of conduction slowing. Criteria suggestive of acute demyelination (Table 2) have been modified from those initially proposed by Kelly, ${ }^{43}$ recognizing that the distinction between "demyelination" and "axonal degeneration" is not always clear.

Evidence of segmental demyelination is present in about $50 \%$ of patients during the first 2 weeks of illness. ${ }^{1,2}$ This increases to $85 \%$ during the third week of illness. Throughout the course

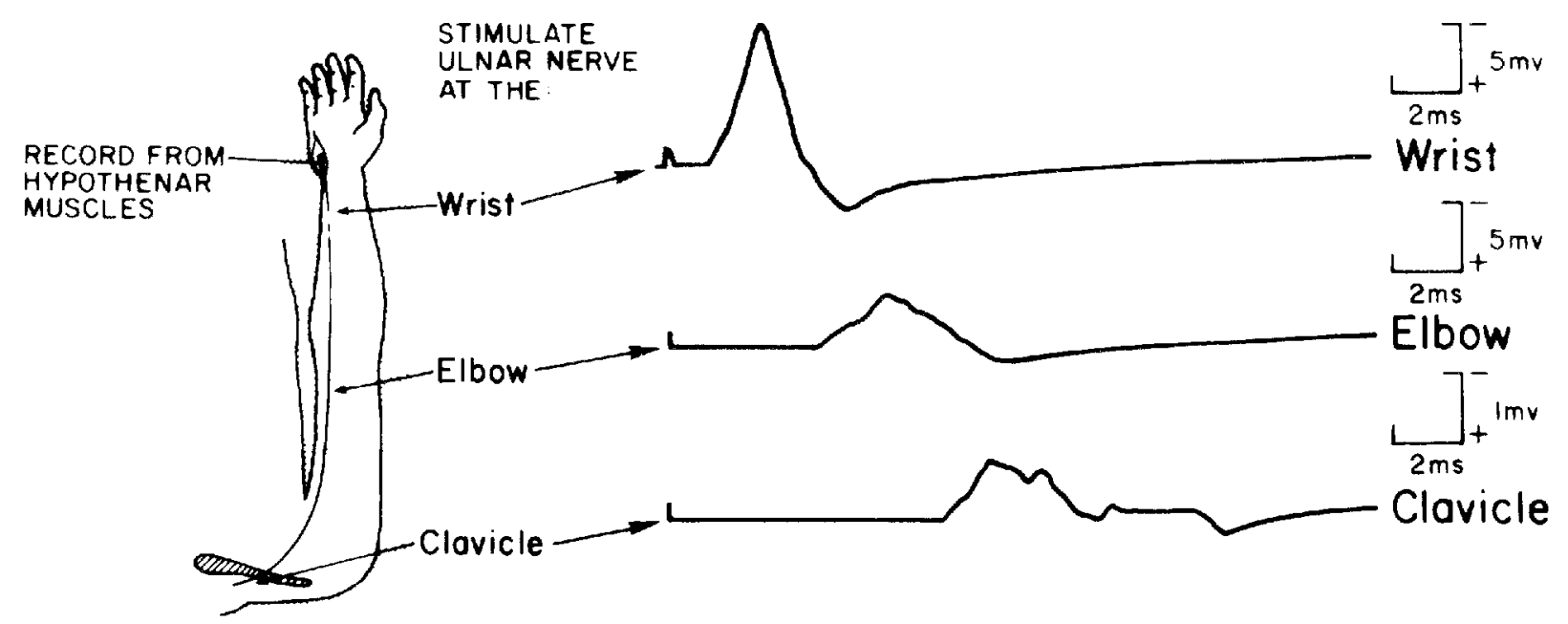

FIGURE 1. Abnormal temporal dispersion with partial conduction block of ulnar compound muscle action potential, recording from hypothenar muscles of patient with acute inflammatory demyelinating polyneuropathy. 
Table 2. Criteria suggestive of demyelination in the electrodiagnostic evaluation of acute inflammatory polyneuropathy.

Demonstrate at least three of the following in motor nerves (exceptions noted below):
1. Conduction velocity less than $90 \%$ of lower limit of normal if amplitude exceeds $50 \%$ of lower limit of normal; less than $80 \%$ if
amplitude less than $50 \%$ of lower limit of normal (two or more nerves) ${ }^{a}$
2. Distal latency exceeding $115 \%$ of upper limit of normal if amplitude normal; exceeding $125 \%$ of upper limit of normal if
amplitude less than lower limit of normal (two or more nerves). ${ }^{b}$
3. Evidence of unequivocal temporal dispersion or a proximal-to-distal amplitude ratio less than 0.7 (one or more nerves)..$^{b, c}$
4. F-response latency exceeding $125 \%$ of upper limit of normal (one or more nerves). ${ }^{a, b}$

Source: Modified and reprinted from Ref. 2 with the permission of John Wiley \& Sons, Inc., Copyright (c) 1985.

"Excluding isolated uinar or peroneal nerve abnormalities at the elbow or knee, respectively.

${ }^{B}$ Excluding isolated median nerve abnormality at the wrist.

${ }^{C}$ Excluding the presence of anomalous innervation (e.g., median to unar nerve crossover).

of AIDP, $10 \%$ of patients never fulfill electrodiagnostic criteria for demyelination because responses are unobtainable. About $3 \%$ of patients studied sequentially demonstrate evidence of axonal degeneration only. Motor nerve abnormalities peak between the third and fourth weeks, although individual patients may demonstrate absent evoked responses within days of onset, presumably reflecting distal conduction block, and/or axonal degeneration. Conversely, some patients demonstrate progressive amplitude loss through the fifth or sixth weeks. Patients having only prolonged distal latencies during the first 3 weeks of illness ${ }^{51}$ may demonstrate partial conduction block and conduction velocity slowing in the following weeks.

The degree of conduction block, not the amount of motor conduction slowing, best correlates with clinical impairment. Sequential CMAP amplitude recordings for proximal and distal stimulation for one patient are shown in Fig. 2. The reduced CMAP amplitude with proximal stimulation (clavicle) cannot be explained by temporal dispersion alone and likely represents partial conduction block. Early recordings demonstrated progressivcly decreasing amplitudes, reflecting axonal degeneration or progressive conduction block. During subsequent recordings when the neurologic impairment was unchanged, the evoked amplitude with distal stimulation improved dramatically. This rapid improvement cannot be explained by axonal regeneration or collateral rcinnervation but is explainable by reversal of distal conduction block.

During the first few weeks of illness, motor abnormalities are much more common than sensory abnormalities. Motor and sensory evoked amplitudes expressed as a percentage of the normal mean were averaged for 70 patients with AIDP (34 patients had sequential evaluations) versus time after disease onset and are shown in Fig. 3. ${ }^{2}$ Although almost $90 \%$ of patients have some mo- tor conduction abnormalities during the first few weeks of illness, only $25 \%$ of patients have sensory abnormalities during the same interval. By the third week, however, almost $80 \%$ of patients had abnormal sensory studies. Motor abnormalities for a given patient tended to be homogeneous, with the lower limbs showing greater involvement than the upper limbs. Conversely, sensory studies frequently demonstrated abnormalities of individual nerves. Sural and median sensory conduction studies are shown in Table 3. During initial evaluation, a common finding was an abnormal median sensory response with normal sural nerve conduction studies. ${ }^{69}$ The median sensory nerve action potential (SNAP) usually was absent or markedly reduced in amplitude with prolonged distal latency. Patients with an abnormal sural and normal median sensory conduction study, a finding characteristic of most mild, chronic polyneuropathies, were uncommon. This finding of a normal, relatively spared sural response in the presence of an abnormal median sensory response, in association with the appropriate clinical syndrome, is characteristic of AIDP.

Several explanations exist for the discrepancy between motor and sensory studies as well as the discrepancy between the sural and median sensory conduction studies. Neuromuscular transmission failure following a distal axonal lesion would result in reduced CMAP amplitudes prior to reduction in SNAP amplitudes. If the amount of myelin protected the axon or preserved conduction, the larger myelinated sensory fibers would be preferentially preserved relative to the smaller motor fibers. This also could explain prolonged sural nerve function compared to median sensory function, because the sural recording is obtained from the more proximal nerve as compared with the terminal median sensory fibers. This distal predilection is consistent with reported centripetal demyclination in somc patients ${ }^{95}$ and also consistent 


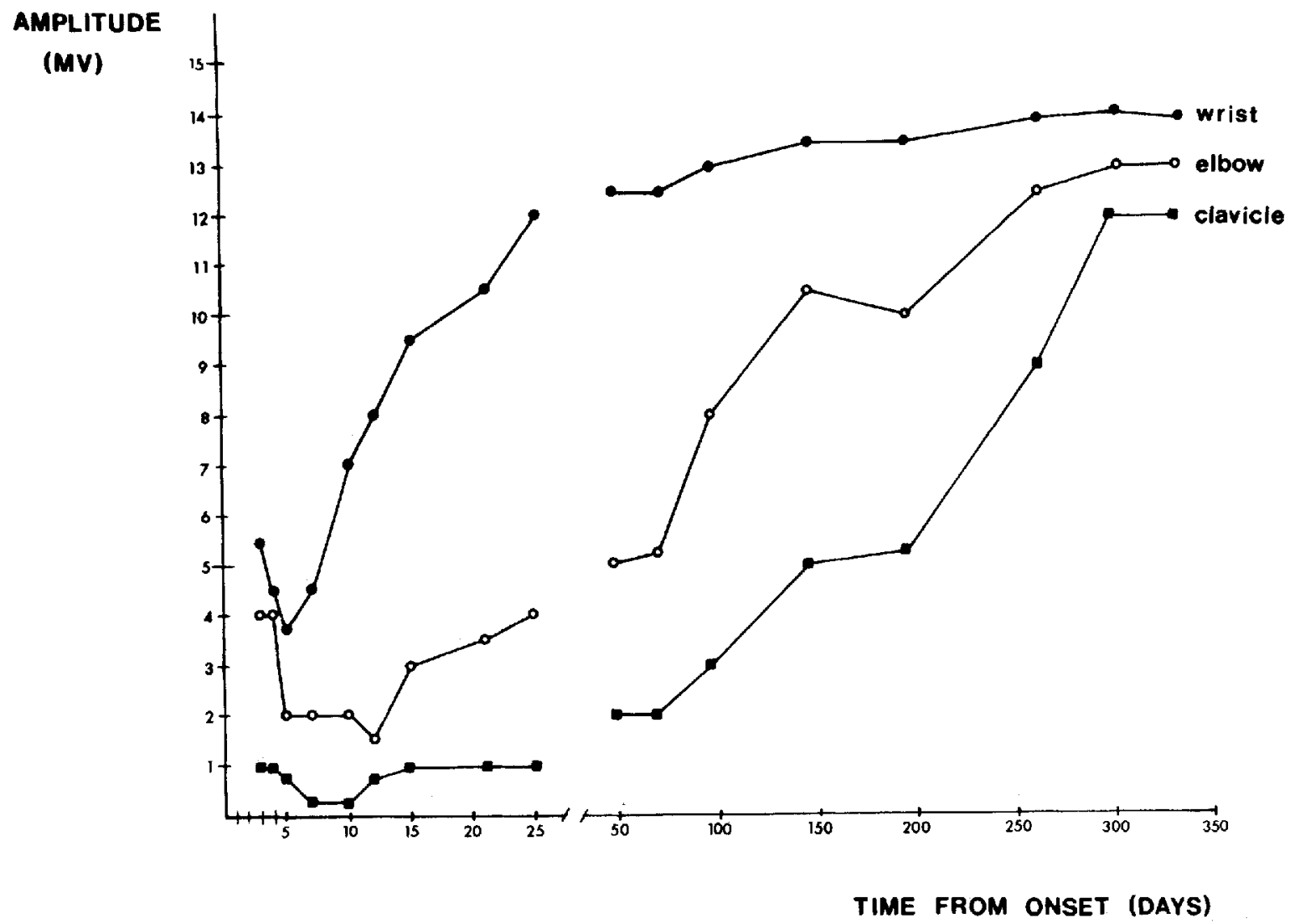

FIGURE 2. Serial ulnar compound muscle action potential amplitudes with proximal and distal stimulation, recording from the hypothenar muscles of a patient with acute inflammatory demyelinating polyneuropathy. Amplitudes (mV) are expressed as a function of time from disease onset. (Reprinted with permission from Albers JW: Electromyography in the prognosis of nerve injury. American Academy of Neurology Special Course \#22: Clinical Electromyography, 1980.)

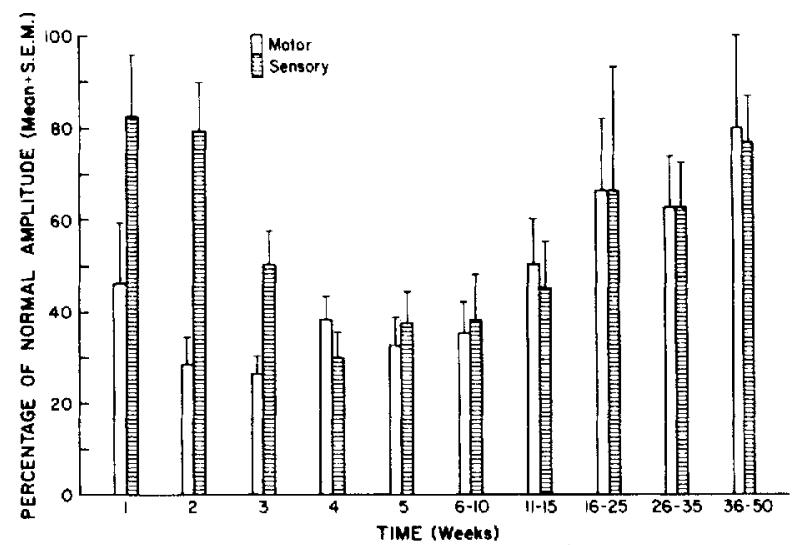

FIGURE 3. Motor- (open bar) and sensory- (shaded bar) evoked response amplitudes expressed as a percentage of the normal mean as a function of time after disease onset in 70 patients with acute inflammatory demyelinating polyneuropathy. The responses are significantly $(P<0.05)$ different for weeks 1,2 , and 3. No significant differences exist thereafter. (Reprinted from Ref. 2 by permission of John Wiley \& Sons, Inc, Copyright (C) 1985.) with the observations of Sumner, ${ }^{89}$ who found, using a humorally induced demyelination in rat sciatic nerve, that smaller diameter myelinated fibers were affected earlier and more completely than larger diameter fibers. Nerve roots were highly permeable to antiserum, and distal motor nerve twigs and common compression sites were identified as potential areas of vulnerability because of an impaired blood-nerve barrier.

Electromyography (EMG) has a secondary role in evaluating patients with AIDP. Decreased motor unit action potential (MUAP) recruitment, without evidence of configuration abnormalities or abnormal spontaneous activity, is the initial finding, reflecting the clinical distribution of weakness. Occasionally, myokymic discharges are observed during the first few weeks of illness. ${ }^{18}$ They may be found in facial or extremity muscles and may be present in the absence of clinical myokymia. Fibrillation potentials and positive waves appear between 2 and 5 wceks, simultaneously in proximal and distal muscles (Fig. 4), consistent with either 
Table 3. Comparison of median and sural sensory conduction studies in patients with acute inflammatory demyelinating polyneuropathy: results at the time of initial and follow-up evaluation.

\begin{tabular}{lccc}
\hline & All studies $(n=86)$ & Initial eval. first 3 weeks $(n=39)$ & Follow-up $(n=39)$ \\
\hline Both normal & $30(35 \%)$ & $11(28 \%)$ & $13(33 \%)$ \\
Both abnormal & $20(23 \%)$ & $9(23 \%)$ & $13(33 \%)$ \\
Median abnormal and sural normal & $36(42 \%)$ & $19(49 \%)$ & $13(33 \%)$ \\
Median normal and sural abnormal & $0(0 \%)$ & $0(0 \%)$ & $0(0 \%)$ \\
\hline
\end{tabular}

Source: Modified and reprinted from Ref. 2 with the permission of John Wiley \& Sons, Inc., Copyright (c) 1985.

random axonal degeneration at any point along the axon or predominant distal involvement. Proximal fibrillation potentials are maximal between 6 and 10 weeks, with distal fibrillation potentials persisting for many months. 'The amount of abnormal spontaneous activity ranges from none to extensive denervation with profuse $(4+)$ positive waves and fibrillation potentials. The early reduction in fibrillation potentials in proximal compared with distal muscles likely reflects reinnervation from axonal sprouting or regeneration in proximal compared with distal muscles. This can be explained both by the greater probability of regeneration in a short axon and by the increased likelihood of collateral reinnervation from a greater number of surviving axons.

Prognostic Indicators. Clinical and CSF findings are poor predictors of outcome in patients with AIDP. ${ }^{74}$ A prolonged interval to onset of recovery indicates a poor prognosis, ${ }^{60}$ as does rapid evolution of weakness and ventilator dependency. ${ }^{66}$

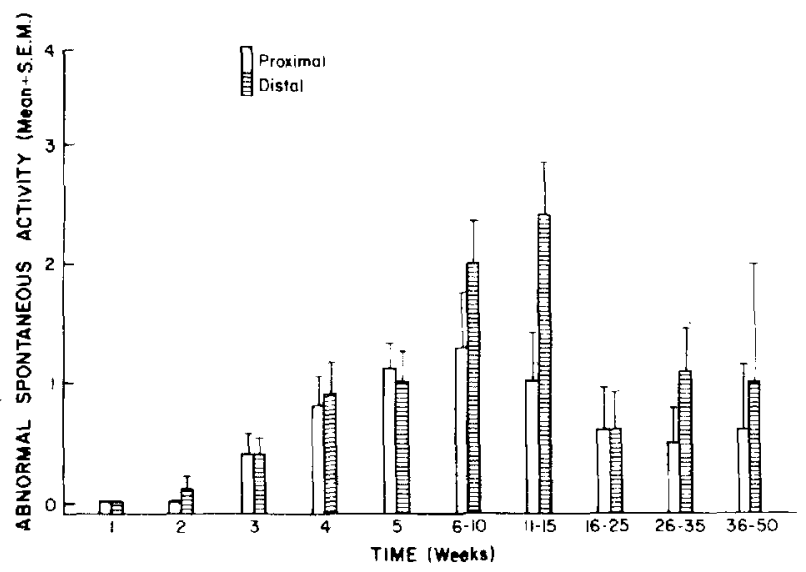

FIGURE 4. Abnormal spontaneous activity in proximal (open bar) and distal (striped bar) muscles as a function of time after disease onset in 70 patients with acute inflammatory demyelinating polyneuropathy. Fibrillation potential scores range from 0 to $4+$, with $0=$ none and $4+=$ profuse fibrillation potentials in all areas of muscle. (Reprinted from Ref. 2 by permission of John Wiley \& Sons, Inc., Copyright C 1985.)
Nevertheless, some ventilator-dependent patients recover promptly and completely, whereas seemingly identical patients havi: a prolonged recovery. The most powerful predictor of poor outcome is reduced CMAP amplitude to less than $10 \%$ of the lower limit of normal. ${ }^{66}$ Neurologic recovery is positively and significantly correlated with preserved mean CMAP amplitude, when the studies are performed between weeks 3 and 5 . These findings support the hypothesis that evidence suggestive of predominant demyelination is correlated with relatively rapid recovery, whereas findings suggestive of severe axonal destruction are correlated with slow recovery ${ }^{66.73}$ The amount of fibrillation is a relatively poor predictor of prognosis when used alone.

Treatment. The supportive treatment of patients with AIDP involves maintenance of respiratory function and prevention of circulatory failure and thromboembolism. ${ }^{4}$ The advent of respiratory intensive care units has been important in preserving life, although a mortality rate of approximately $5 \%$ persists even with aggressive pulmonary treatment. Most dcaths follow medical complications of respiratory paralysis, including pneumonia. ${ }^{42}$ Approximately half of patient deaths are sudden, presumably related to cardiac dysrhythmias or hypotension. All patients require observation for respiratory deterin ration. The decision of whether or not to intubate a patient depends upon both the extent and rate of respiratory deterioration. General thresholds are difficult to define, but intubation and respirator support generally are needed if the forced vital capacity falls below $15 \mathrm{ml} / \mathrm{kg}$. Elective intubation should be performed if there is a rapid decline of vital capacity, early signs of hypoxia, aspiration with poor tracheopulmonary toilet, pulmonary infection with shunting, or signs of respiratory distress or fatigue. Arterial blood gases represent a poor measure of respiratory function, deteriorating late in the clinical course. A low $\mathrm{PO}_{2}$ and low or normal 
$\mathrm{PCO}_{2}$ indicates shunting from early atelectasis and often precedes respiratory failure. Hypercapnia is a late finding of respiratory failure and dangerous criterion for elective intubation. Prolonged intubation without tracheostomy is now possible with soft endotrachial tubes, although meticulous tracheopulmonary toilet is facilitated by tracheostomy, and the use of a talking tracheostomy may facilitate psychological care.

Autonomic instability requires monitoring in an intensive care setting. Hypotension is best managed by increasing fluids, and sympathomimetics usually are avoided. Hypertension is best not treated unless severe. When necessary, medications with a short half-life such as nitroprusside or propanalol are preferred. The most common cardiac dysrhythmias are a second- or third-degree AV block. Temporary pacemaker insertion is an effective treatment.

Additional medical management includes proper bladder care, prompt identification and treatment of superimposed infection, restriction of fluids in patients who are hyponatremic, and antiembolism protection, including low-dose heparin (5000 units subcutaneous twice daily) and antiembolus stockings in quadriparetic patients. Appropriate laboratory studies should be performed, monitoring for occult blood loss, anemia and thrombocytopenia, infection, and electrolyte imbalance.

Corticosteroids are of unproven efficacy in AIDP, and their use is controversial. The most recent controlled study ${ }^{39}$ reported that prednisone may have slowed the recovery rate and increased the chance of relapse. Anecdotal reports ${ }^{24}$ exist of single patients who responded dramatically to steroids.

The potential importance of humoral factors in the pathogenesis of AIDP suggested that therapeutic plasma exchange (TPE) might modify the disease course. ${ }^{68}$ The multicenter randomized trial of TPE in the treatment of AIDP ${ }^{90}$ demonstrated significant benefit of TPE when compared with conventional medical treatment, excluding steroids. By all criteria, TPE had a beneficial effect. The median time on a respirator was reduced by 11 days and the time to unassisted ambulation shortened by an average of 73 days for respirator-dependent patients who received TPE. Similar results have been reported in two additional controlled, randomized trials. ${ }^{15,71}$ Two smaller controlled trials were inconclusive, although the trends favored the TPE group. ${ }^{32,65}$ TPE is not effective for all patients. Patient age and the CMAP amplitudes are important predictors of early responsiveness. ${ }^{34}$ TPE appears particularly effective for patients who begin treatment within 7 days of disease onset, although early, aggressive TPE may be associated with initial improvement followed by relapse, perhaps related to termination of treatment too early in the course of the discase. ${ }^{82}$

\section{CHRONIC INFLAMMATORY DEMYELINATING POLYNEUROPATHY}

Clinical Features. CIDP is a chronic progressive or relapsing disorder of peripheral nerves that clinically resembles AIDP. Reliable incidence estimates are unavailable, although it is probably less than that of AIDP. Because of the prolonged course, however, the prevalence probably exceeds that of AIDP. CIDP occurs in both sexes and all ages with little evidence of peaks other than a predominance in the fifth and sixth decades. ${ }^{77}$

Diagnostic criteria differ only slightly for those used for AIDP. At present, the only reliable method for differentiating the two disorders is by an arbitrary clinical judgment regarding the temporal evolution of neurologic symptoms. Patients with CIDP usually have an interval between onset and peak impairment exceeding 4 weeks, and the average duration from onset to peak deficit averages approximately 3 months, with a range of 3 weeks to 16 months. ${ }^{77}$

CIDP is characterized by sensory loss and weakness, areflexia, elevated CSF protein, and electrodiagnostic evidence of multifocal demyelination with or without superimposed axonal degeneration. ${ }^{5,26,91}$ 'The etiology is unknown, but the results of nerve biopsy and reports of response to steroids, ${ }^{17,91}$ azathioprine, ${ }^{77,94}$ or $\mathrm{TPE}^{53,84,85,92}$ suggest an immunologic etiology. ${ }^{56}$ An identifiable antecedent event is rare compared with AIDP, although GIDP has been associated with immune complexes of hepatitis B virus. ${ }^{41}$

Symmetric sensory and/or motor symptoms are the initial manifestation, and weakness usually begins in the legs. Rarely, asymmetric findings are present, consistent with multifocal demyelinating mononeuropathies. ${ }^{55}$ Cranial nerve involvement is common, especially orbicularis oculi weakness, but less prominent than in AIDP. Maximal weakness usually is distal, and 15 of the 23 patients described by Prineas and McLeod ${ }^{77}$ were nonambulatory during their most severe episode. Occasional patients require respiratory support, either during an exacerbation or during the terminal phase. Muscle wasting may be severe but often is 
mild compared with the degree and severity of muscle weakness. Sensory symptoms and signs usually are mild but may be associated with a sensory ataxia. All modalities of sensation may be affect$\mathrm{ed}{ }^{77}$ although large fiber loss predominates. Muscle stretch reflexes are usually absent at some time during the illness; rare patients fulfill all other diagnostic criteria but have hypoactive, preserved reflexes. Autonomic involvement is uncommon.

The clinical course in CIDP is variable. The term chronic relapsing polyneuropathy (CRP) has been used to describe patients with clear relapses and remissions. Dyck and associates ${ }^{26}$ estimated that approximately $50 \%$ of patients had a progressive course (slow or stepwise), one-third had a relapsing course, and the remaining patients experienced a monophasic illness with the peak deficit remaining or developing after 6 months. With current treatments, many patients who may have had progressive disease seemingly respond to treatment but relapse when therapies are tapered or discontinued. The distinction between therapyassociated relapse in CIDP and idiopathic relapse in CRP is unclear.

In CRP, the average interval between relapses is about 10 months, although relapses have been reported 31 years after initial attacks. ${ }^{77}$ Patients with CRP may remit after many years, without further exacerbations. In early reports of outcome for 53 patients with CIDP who were followed for an average of 7 years, 9 died (6 from the disease), 6 were confined to wheelchair or bed, 36 had a mild to moderately severe impairment, and only 2 had complete resolution. ${ }^{26}$ Recent experience suggests that more patients experience remission, with fewer patients demonstrating progressive deterioration. This may reflect earlier detection and treatment or recognition of milder cases.

Electrophysiologic Features. The electrodiagnostic findings in CIDP resemble those described late in the course of AIDP and are consistent with multifocal demyelination with variable amounts of superimposed axonal degeneration. The chronic progressive, stepwise progressive, and relapsing forms cannot be differentiated electrophysiologically. Electrodiagnostic criteria suggestive of demyelination in CIDP (Table 4) differ slightly from those described for AIDP. These differences reflect the possible development of axonal stenosis or regeneration, changes that may result in substantial conduction slowing without segmental demyelination. Nevertheless, electrodiagnostic evidence of demyelination is present in virtually all patients with CIDP, and many consider this part of the diagnostic criteria. ${ }^{1}$ Motor conduction velocities may be markedly reduced, $F$ response latencies very prolonged (or absent), and temporal dispersion more prominent than observed in AIDP, although individual variations are large. The combination of absent or abnormal SNAPs with normal sural responses occurs but is uncommon in CIDP compared with AIDP. EMG abnormalities are present in most patients with CIDP. Like AIDP, needle examination is useful for defining the chronicity and extent of axonal degeneration.

Treatment. The supportive care of patients with CIDP is identical to that described for AIDP. Unlike AIDP, corticosteroids are of demonstrated benefit in controlled trials of both the CRP and CIDP. ${ }^{8,26,27,77,91}$ Many prednisone treatment protocols exist, including high-dose daily or alternateday schedules, with slow taper depending upon clinical response. Azathioprine also has been reported to be effective in several case reports and small clinical trials of CIDP patients, ${ }^{94}$ including patients previously steroid unresponsive or intolerant. $^{72}$

Isolated case reports described TPE as beneficial in CIDP. ${ }^{33,53,61,84} \mathrm{~A}$ consecutive patient trial of TPE demonstrated substantial clinical improvement within 3 weeks in about $50 \%$ of progressive CIDP patients. ${ }^{22}$ The temporal association between improvement and TPE in patients with

Table 4. Criteria suggestive of demyelination in the electrodiagnostic evaluation of chronic inflammatory polyneuropathy.

\footnotetext{
Evaluation should satisfy at least three of the following in motor nerves (exceptions noted below):

1. Conduction velocity less than $75 \%$ of the lower limit of normal (two or more nerves). ${ }^{\text {a }}$

2. Distal latency exceeding $130 \%$ of upper limit of normal (two or more nerves). ${ }^{\text {b }}$

3. Evidence of unequivocal temporal dispersion or conduction block on proximal stimulation consisting of a proximal-to-distal amplitude ratio less than 0.7 (one or more nerves). ${ }^{b, c}$

4. F-response latency exceeding $130 \%$ of upper limit of normal (one or more nerves). ${ }^{\text {ab }}$
}

aEciuding isolated uinar or peroneai nerve abnormalities at the elbow or knee, respectively.

${ }^{b}$ Excluding isolated median nerve abnormality at the wrist.

'Excluding the presence of anomalous innervation (e.g., median to unar nerve crossover). 
longstanding, progressive deterioration seemed more than coincidental. A subsequent prospective double-blind trial in which patients with static or progressive CIDP were randomized to TPE or sham exchange groups demonstrated significant improvement in electrodiagnostic and clinical measurements after 3 weeks, favoring patients receiving TPE. ${ }^{25}$

\section{DYSPROTEINEMIC OR PARANEOPLASTIC NEUROPATHIES}

A subset of patients with acquired demyelinating polyneuropathy exists which differs from CIDP only by the presence of an underlying systemic illness. Because the systemic illness may not be apparent when the polyneuropathy is diagnosed, these patients often are classified as having CIDP or even AIDP, although most clinicians restrict these terms to exclude patients with systemic illness. Included are patients with Waldenstrom's macroglobulinemia, ${ }^{19}$ gamma heavy chain disease, ${ }^{50}$ cryoglobulinemia, ${ }^{58}$ lymphoma, ${ }^{20}$ systemic lupus erythematosus, ${ }^{26}$ Castleman's disease, ${ }^{14}$ and HIVI infections. 57,67
Acquired demyelinating polyneuropathy rarely can be due to an occult malignancy. ${ }^{16}$ The polyneuropathy with malignancy can be motor dominant, distal and/or proximal in distribution, evolve rapidly or slowly, and develop a relapsing or remitting course. EMG and pathologic studies are the same as in idiopathic cases. The etiology is assumed to be an immunologic process triggered by the underlying malignancy. The association is rare, however, and there is no reason to routinely evaluate all patients for a malignancy. Far more common is the association of an acquired demyelinating polyneuropathy and a plasma cell dyscrasia syndrome. Because of the high prevalence compared with other systemic disorders, these syndromes will be described further below.

Demyelinating Polyneuropathy Encountered in the Plasma Cell Dyscrasia Syndromes. All idiopathic: polyneuropathy patients, and particularly those with presumed CIDP, should be evaluated for possible occult plasma cell dyscrasias. ${ }^{44}$ A suggested approach is detailed in Table 5. Up to $10 \%$ of patients with idiopathic polyneuropathy harbor

Table 5. Flow chart for evaluation of polyneuropathy patient

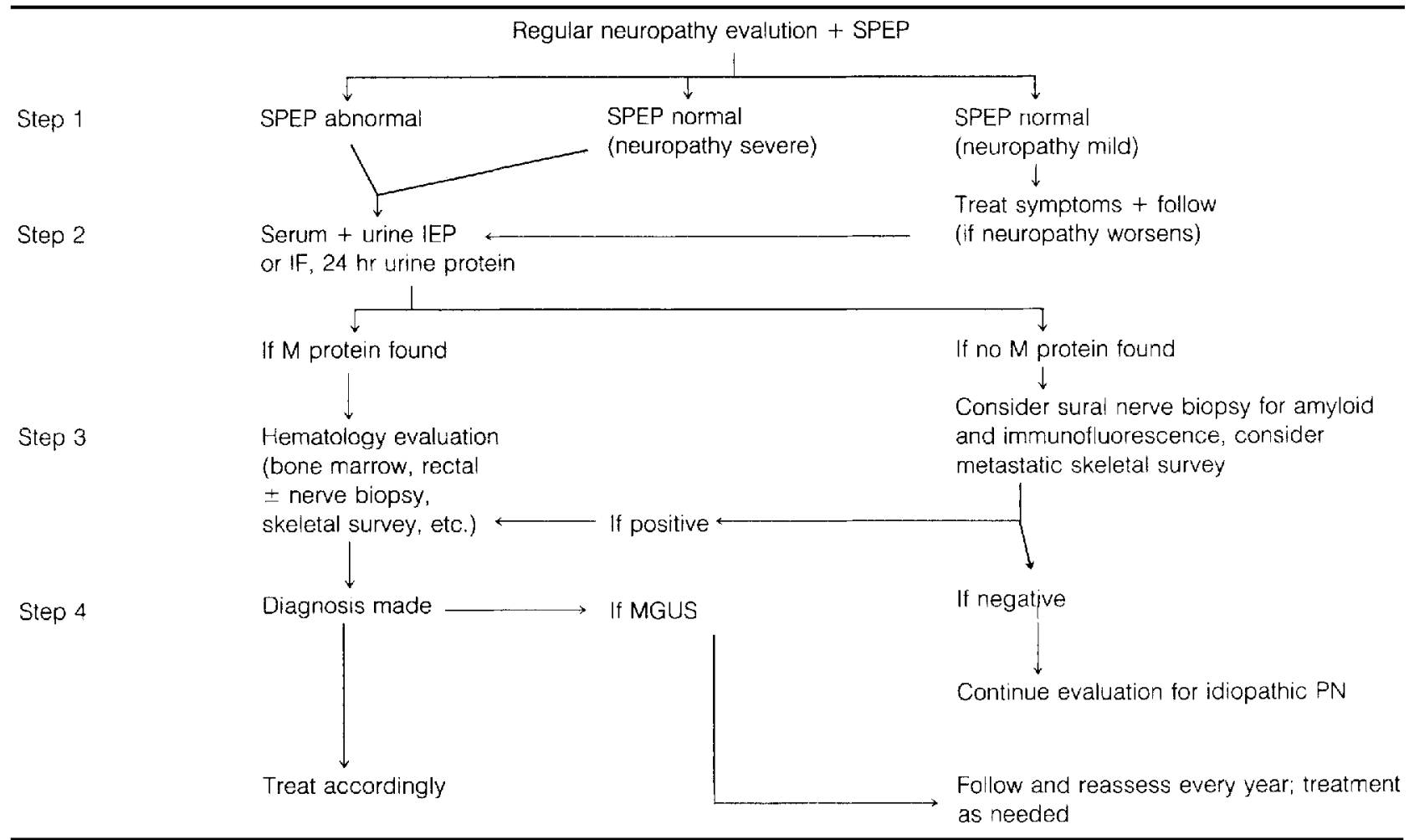

SPEP $=$ serum protein electrophoresis, iEP = immunoelectrophoresis, if = immunotixation, MGUS = monocional gammopathy.

Source: Reprinted with permission from Kelly JJ: Polyneuropathies associated with plasma cell dyscrasias, in Brown MJ (ed): Seminars in neurology Neuropathy 7:30-39, 1987. 
Table 6. Features of polyneuropathy $M$ protein syndromes.

\begin{tabular}{|c|c|c|c|c|c|c|c|c|}
\hline $\begin{array}{c}\text { Type of } \\
\text { polyneuropathy }\end{array}$ & Topography & Weakness & $\begin{array}{l}\text { Sensory } \\
\text { loss }\end{array}$ & $\begin{array}{l}\text { Autonomic } \\
\text { loss }\end{array}$ & Course & $\begin{array}{l}\text { CSF protein } \\
\text { elevation }\end{array}$ & Pathology & EMG \\
\hline MGUS (igM) & Distal, symmetric & ++ & +++ & 0 & Chronic & ++ & SD & Slow CV \\
\hline $\begin{array}{l}\text { MGUS } \\
\qquad(\lg G, \lg A)\end{array}$ & $\begin{array}{c}\text { Distal, rarely } \\
\text { proximal }\end{array}$ & $+t$ & ++ & + & Chronic & ++ & $\mathrm{SD}$ & $\begin{array}{l}\text { Slow or mildly slow } \\
\mathrm{CV}\end{array}$ \\
\hline$A L$ & Distal, symmetric & $+1++$ & $+t+$ & ++ & Chronic & \pm & $A D$ & Mildly slow CV \\
\hline OSM & Distal, symmetric & $+t+$ & ++ & 0 & Chronic & $+t+t+$ & $\begin{array}{l}S D \\
\text { (AD) }\end{array}$ & Slow CV \\
\hline WM & Distal, symmetric & ++ & ++ & 0 & Chronic & ++ & $\mathrm{SD}$ & Slow CV \\
\hline
\end{tabular}

Note: $0=$ none, $\pm=$ equivocal or occasional, $+=$ minimal,$++=$ moderate, $+++=$ marked, MGUS $=$ monocional gammopathy, AL $=$ amyloidosis, $O S M=$ osteosclerotic myeloma, $W M=$ Waldenstrom's macroglobulinemia, $S D=$ segmental demyelination, $A D=a x o n a l$ degeneration, $C V=$ conduction velacily

Source: Reprinted with permission from Kelly JJ: Polyneuropathies associated with plasma cell dyscrasias, in Brown MJ (ed): Seminars in neurology Neuropathy 7:30-39, 1987

an occult plasma cell dyscrasia which may directly relate to the etiopathogenesis of the neuropathy and respond to treatment. These patients are of investigational importance because the monoclonal protein may cause the polyneuropathy. The features of the polyneuropathy in the different plasma cell dyscrasia syndromes are summarized in Table 6.

Primary systemic amyloidosis of the amyloid light-chain type forms an important subset of the plasma cell dyscrasia syndromes. The polyneuropathy, however, is axonal and usually involves small fibers without evidence of conduction slowing, and therefore should not be confused with the demyelinating dysimmune polyneuropathies. Similarly, typical multiple myeloma is associated with a very high monoclonal protein level, widespread lytic skeletal lesions, anemia, and hypercalcemia. It is rarely associated with polyneuropathy. ${ }^{47}$ When it is, polyneuropathy is heterogeneous in type with little relationship to the status of the myeloma.
Monoclonal Gammopathy of Undetermined Significance. In evaluating patients with presumed CIDP, a monoclonal gammopathy occasionally is identified. This hematologic disorder, referred to as monoclonal gammopathy of undetermined significance (MGUS), was formerly called "benign monoclonal gammopathy" but was renamed because up to $20 \%$ of these patients develop more serious hematologic disease or secondary changes elsewhere, including neuropathy. ${ }^{49} \mathrm{By}$ definition, these patients have a low monoclonal protein concentration ( $<3 \mathrm{~g} / \mathrm{dl}$ ), no malignant plasma cell infiltration of the bone marrow, and no bony lesions (Table 7). This group accounts for about one-half of plasma cell dyscrasia, polyneuropathy patients (Table 8).

Patients with MGUS-associated neuropathy include $\operatorname{IgM}$ and non-IgM types. The $\operatorname{IgM}$ group is of interest because one-half of these patients have a characteristic polyneuropathy, and the monoclonal immunoglobulin possesses antinerve activity, most commonly directed at an antigen on the

Table 7. Hematologic diagnostic criteria of $M$ protein syndromes.

\begin{tabular}{|c|c|c|c|c|c|c|}
\hline Syndrome & Anemia & M protein serum & $M$ protein urine & Bone marrow & Skeletal survey & Tissue biopsy \\
\hline MGUS & No & $t^{*}$ & \pm & \pm & Norma & - \\
\hline $\mathrm{AL}$ & $+1++$ & ++ & + & + & Normal & ++ (amyloid) \\
\hline MM & $+t+$ & $+++^{\star \star}$ & ++ & +++ & Abnormal (lytic) & $+++($ myeloma $)$ \\
\hline OSM & No & $+{ }^{\star} \lambda$ & No & $++1+++$ & Abnormal (sclerotic) & +++ (sclerotic myeloma) \\
\hline WM & +++ & $++t^{* *}$ & \pm & $++1++t$ & \pm & - \\
\hline GAMMA-HCD & +++ & + & + & ++ & $\bar{N}$ & - \\
\hline
\end{tabular}

Note: $\pm=$ equivocal or occasional, $+=$ rare, $++=$ common, $+++=$ almost always or severely abnormal, MM $=$ multiple myeloma, Gamma-HCD $=$ gamma heavy-chain disease, other abbreviations same as Table 6

* Less than 3 g per decilter.

* More than 3 g per deciliter.

$\lambda=$ Almost always lambda light chain

Source: Reprintcd with permission from Kelly JJ: Polyneuropathies associated with olasma cell dyscrasias, in Brown MJ (ed): Seminars in neurology. Neuropathy $7: 30-39,1987$ 
Table 8. Final hematologic diagnosis in 28 patients with polyneuropathy and $M$ proteins.

Monoclonal gammopathy of undetermined significance Amyloidosis, light-chain type

Myeloma (including osteosclerotic cases)

Waldenstrom's macroglobulinemia

Gamma heavy-chain disease

Total

Source: Reprinted with permission from Ref. 46

myelin sheath. ${ }^{36.52}$ The vast majority of patients with antinerve-reactive IgM polyneuropathy have a slowly progressive, sensory polyneuropathy which superficially resembles the sensory neuronopathy syndrome seen with cancer. These neuropathies, however, tend to be much more chronic and indolent, and weakness and atrophy may develop when the neuropathy is advanced. Pansensory impairment with sensory ataxia occurs. Other cases are very mild and nonprogressive over several years. Electrodiagnostic findings differentiate these patients from those with pure sensory neuronopathy. Motor conduction is markedly slowed in the range associated with segmental demyelination, ${ }^{36}$ and CMAP amplitudes are reduced. Needle EMG confirms loss of motor axons. The CSF protein is usually markedly elevated unless the polyneuropathy is very mild.

Nerve biopsy demonstrates combined axonal degeneration and demyelination. Direct immunofluorescent staining for immunoglobulins ${ }^{37}$ shows deposition of monoclonal IgM (Fig. 5) on the myelin sheath. The monoclonal protein is almost always of the kappa light-chain type. Studies have demonstrated in vitro reactivity of this immunoglobulin with myelin-associated glycoprotein (MAG) and other carbohydrate epitopes of glycoproteins or glycolipids on the myelin sheath. ${ }^{40}$

Treatment with immunosuppressives and TPE decreases the immunoglobulin level and patients may improve (Ref. 87 and Kelly et al., unpublished). Injection of serum from these patients into animal nerves causes focal demyelination. ${ }^{37}$ Rarely, other IgM polyneuropathies are associated with axonal degeneration, and IgM is deposited on axons and perineurial tissue. Studies have shown in vitro reactivity with axonal pellets and axonal antigens such as chondroitin sulfate. ${ }^{86}$

Patients with nonreactive IgM neuropathies form a more heterogeneous group. Some closely resemble MAG-reactive polyneuropathies, and some resemble axonal neuropathy. They may re- spond to immunosuppression. The mechanism of nerve fiber damage is unknown.

Patients with the IgG or IgA polyneuropathies are a heterogeneous group, and a relationship, if any, between the gammopathy and polyneuropathy is not clear. Nevertheless, such patients may have an unequivocal demyelinating polyneuropathy indistinguishable from patients with CIDP- or IgM-associated dysimmune neuropathy. Response to immunosuppression is variable. ${ }^{87}$

Osteosclerotic Myeloma. Osteosclerotic myeloma differs from typical multiple myeloma. ${ }^{45}$ Less than $3 \%$ of patients with osteosclerotic myeloma account for about two-thirds of cases of polyneuropathy in large myeloma series; about one-half of all osteosclerotic myeloma patients have a polyneuropathy. Osteosclerotic myeloma is more indolent than multiple myeloma, occurs at a younger age, and is associated with longer survival. The polyneuropathy tends to be slowly progressive, distal, symmetric, and mainly motor, without autonomic dysfunction. CSF protein is very high, and there is frequently papilledema.

Electrodiagnostic findings ${ }^{21,43,45}$ include marked slowing of motor nerve conduction velocities, partial conduction block, and prolonged or absent F-response latencies. SNAPs are decreased or absent. EMG needle examination shows acute and chronic neurogenic changes. Most patients have monoclonal protein of the IgG or IgA and lambda light-chain type, but occasionally, kappa light-chains are present. There are no reports of direct immunofluorescent staining of nerves from these patients, and the monoclonal protein is not MAG-reactive. ${ }^{36}$ Microinjection of the serum into animal nerves does not cause focal demyelination or conduction block. ${ }^{46}$ The key to diagnosis is recognition of the monoclonal protein and bony lesions.

The polyneuropathy resembles monophasic CIDP, and consideration of this diagnosis mandates protein studies and a metastatic skeletal survey. Bony lesions occur in the proximal skeleton and may be sclerotic or mixed sclerotic and lytic (Fig. 6). Biopsy of any suspicious lesion is mandatory. Treatment depends on the nature of the plasmacytoma. If solitary, surgical extirpation or radiation therapy is indicated, and patients improve following effective treatment. Many, or possibly all, eventually relapse. If lesions are multiple, chemotherapy occasionally provides benefit. ${ }^{21}$

Some patients ${ }^{9}$ develop widespread findings with polyneuropathy, organomegaly, endocrinop- 


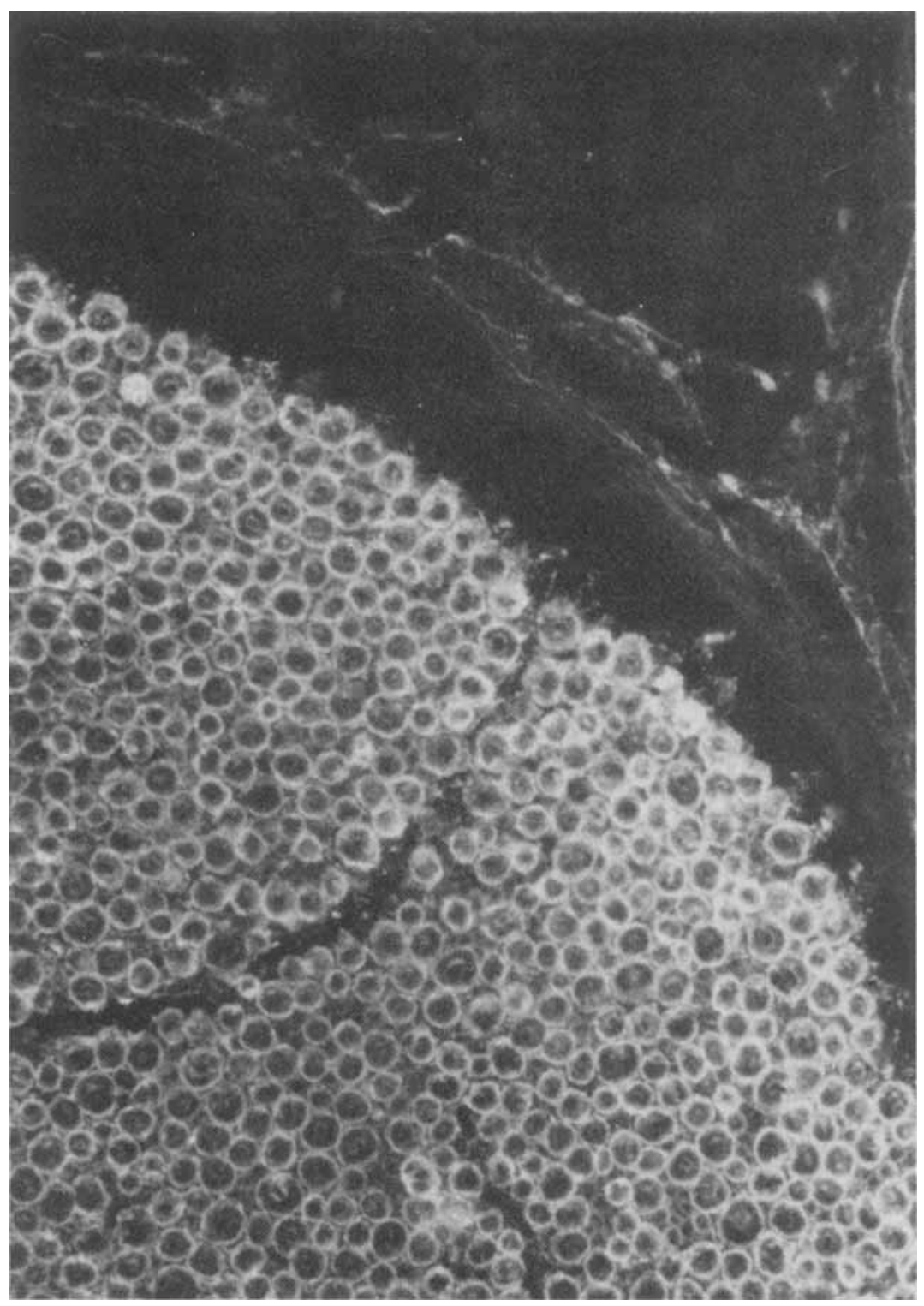

FIGURE 5. Immunofluorescent staining shows intensely stained deposits of IgM especially along the outer lamellae of the myelin sheaths of myelinated axons. Less intense staining is seen around the axon. (Reprinted from Ref. 37 with permission.)
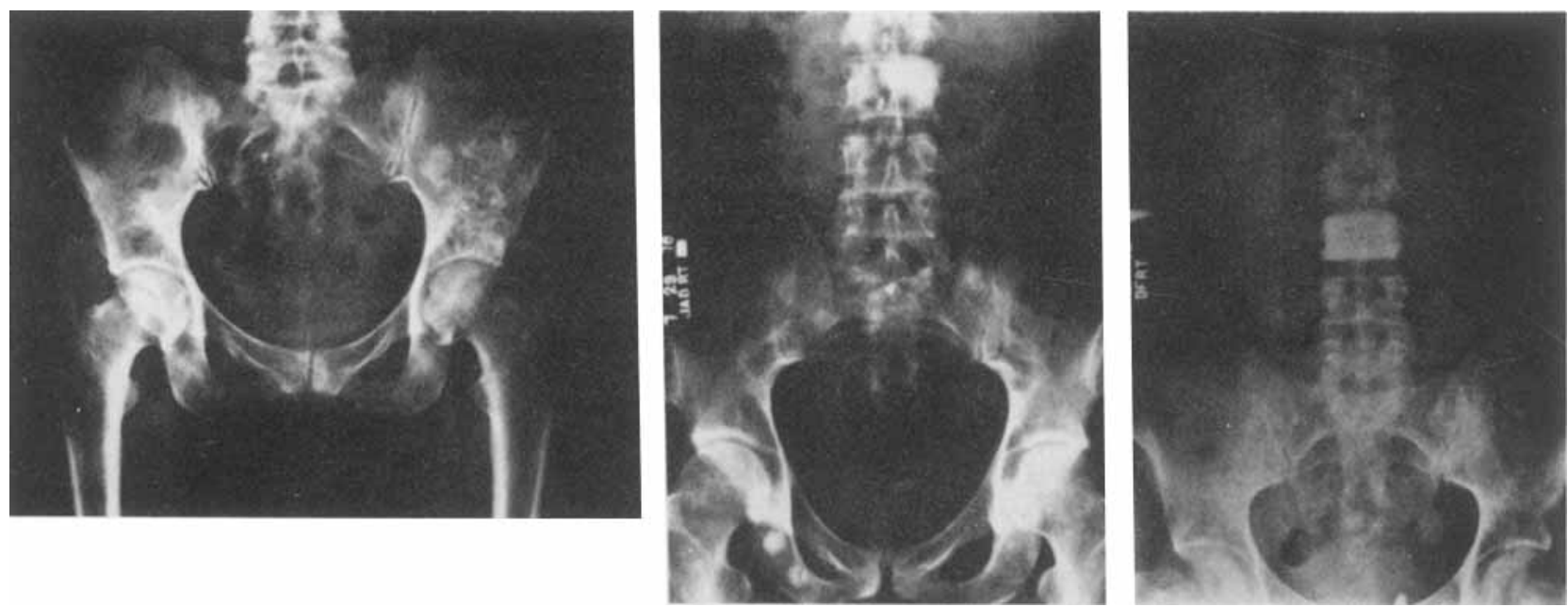

FIGURE 6. Osteosclerotic lesions in patients with polyneuropathy. (A) Mixed lytic and sclerotic lesion of the left ilium in a 56-year-old woman. (B) Multiple sclerotic lesions involving vertebral bodies, sacrum, ischium, and pelvis in a 42-year-old man. (C). "Ivory" L-3 vertebra in a 47-year-old woman. (Reprinted from Ref. 45 with permission.) 
athy, $M$ protein, and skin changes (POEMS syndrome). This multisystem disorder also has been called "Crow-Fukase syndrome" and "Takatsuki's syndrome". ${ }^{70}$ None of these terms is satisfactory because they are too restrictive. Most of these patients have monoclonal proteins of the $\operatorname{IgG}$ or $\operatorname{IgA}$ type with lambda light-chains. One-half to twothirds have osteosclerotic lesions. The common denominator may be the lambda light-chain or some other secretory product of the plasma cell lesion. Thus, osteosclerotic myeloma may be one end of a spectrum, with POEMS at the other.

\section{CONClusion}

Patients with acquired demyelinating polyneuropathies comprise a substantial portion of those patients with undiagnosed polyneuropathies presenting for evaluation. Their importance is disproportionate to their numbers, since many are treatable, some are associated with unrecognized systemic disorders, and most provide clues to the etiopathogenesis of other obscure neuropathies. Although their relationship is unclear, the acute, chronic, and dysimmune inflammatory demyelinating polyneuropathies have characteristic presentations, some of which are easily recognized. Not surprisingly, the electromyographer plays a central role in the evaluation of these patients and is in a position to recognize the patterns of involvement and suggest possible diagnostic alternatives. Thus, the ability to identify an acquired demyelinating polyneuropathy, coupled with a thorough knowledge of these syndromes, is important for any electromyographer who studies neuromuscular patients.

\section{APPENDIX}

Motor Nerve Model: Prediction of Electrodiagnostic Findings in Multifocal Demyelination. A simple model of the peripheral motor nerve can predict electrodiagnostic findings in acute inflammatory demyelinating polyneuropathy (AIDP). This model, together with empiric electrodiagnostic observations, can be used to anticipate the electrodiagnostic findings for acute, multifocal demyelination. The model is represented in Figs. 7-9, consisting of eight axons of variable diameter, ranging from the largest (top) to smallest (bottom). Individual muscle fiber action potentials (MFAPs) are shown to the right of each axon following stimulation of all axons (arrow). Conduction is fastest in the largest and slowest in the smallest axon; the difference in conduction between the largest and smallest fibers constitutes
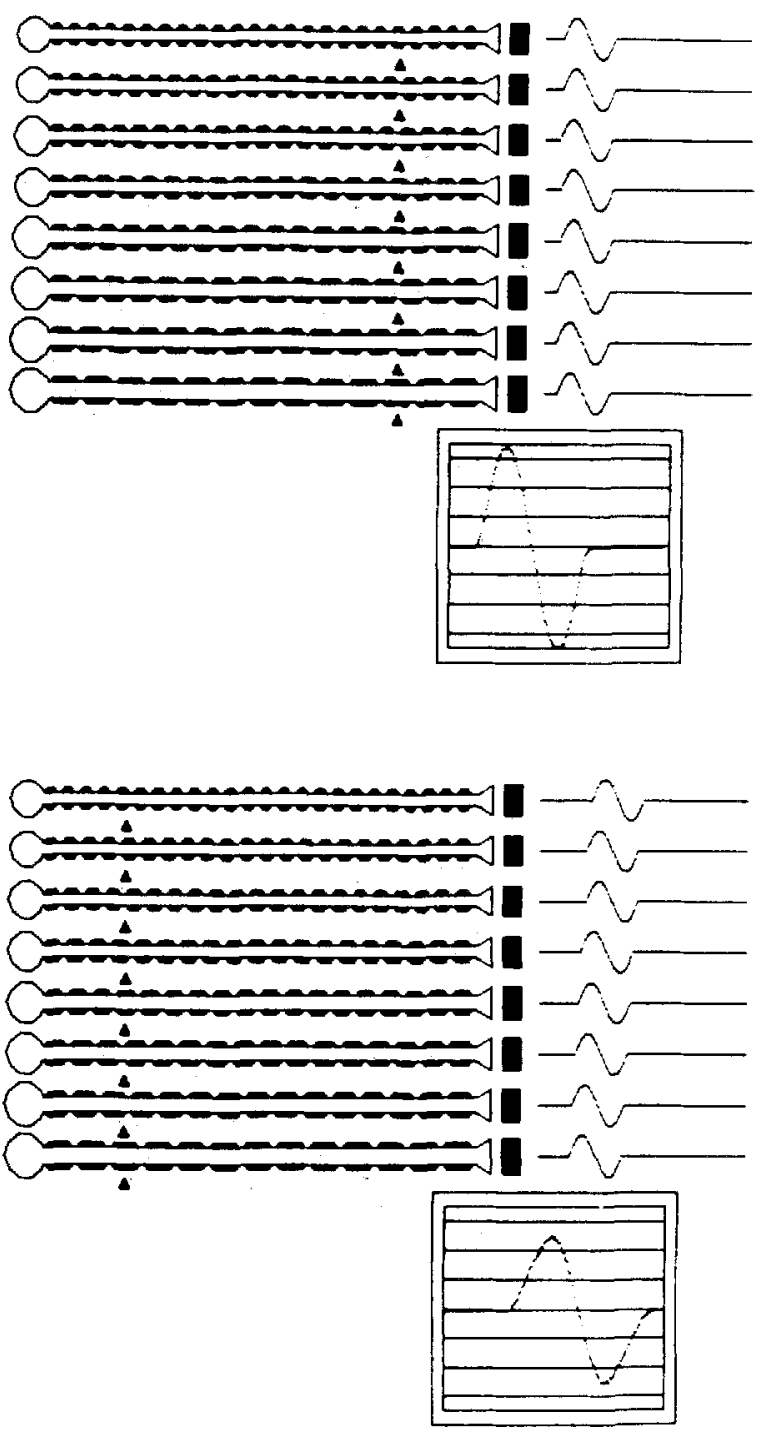

FIGURE 7. Computerized model of peripheral motor nerve, demonstrating summation of eight individual muscle fiber action potentials to produce the compound muscle action potential (CMAP) shown below each nerve in the schematic screen. Individual axons are of slightly different sizes and therefore conduct at different rates. Muscle fibers are denoted by solid bars to the right of each axon. Arrows represent stimulation sites. Upper recording: resultant CMAP following distal nerve stimulation. Lower recording: resultant CMAP following proximal nerve stimulation. (Reprinted from Ref. 1 with the permission of Butterworths, Copyright (c) 1987).

the range of conduction velocities. Individual MFAPs are summed to obtain a compound muscle action potential (CMAP), shown below the modeled nerve. In the figures, the simulated CMAP is demonstrated for distal nerve stimulation (upper half of each figure) and proximal nerve stimulation (lower half of each figure). Latencies could be calculated and a conduction velocity for the fastest axon determined using the distance between stim- 

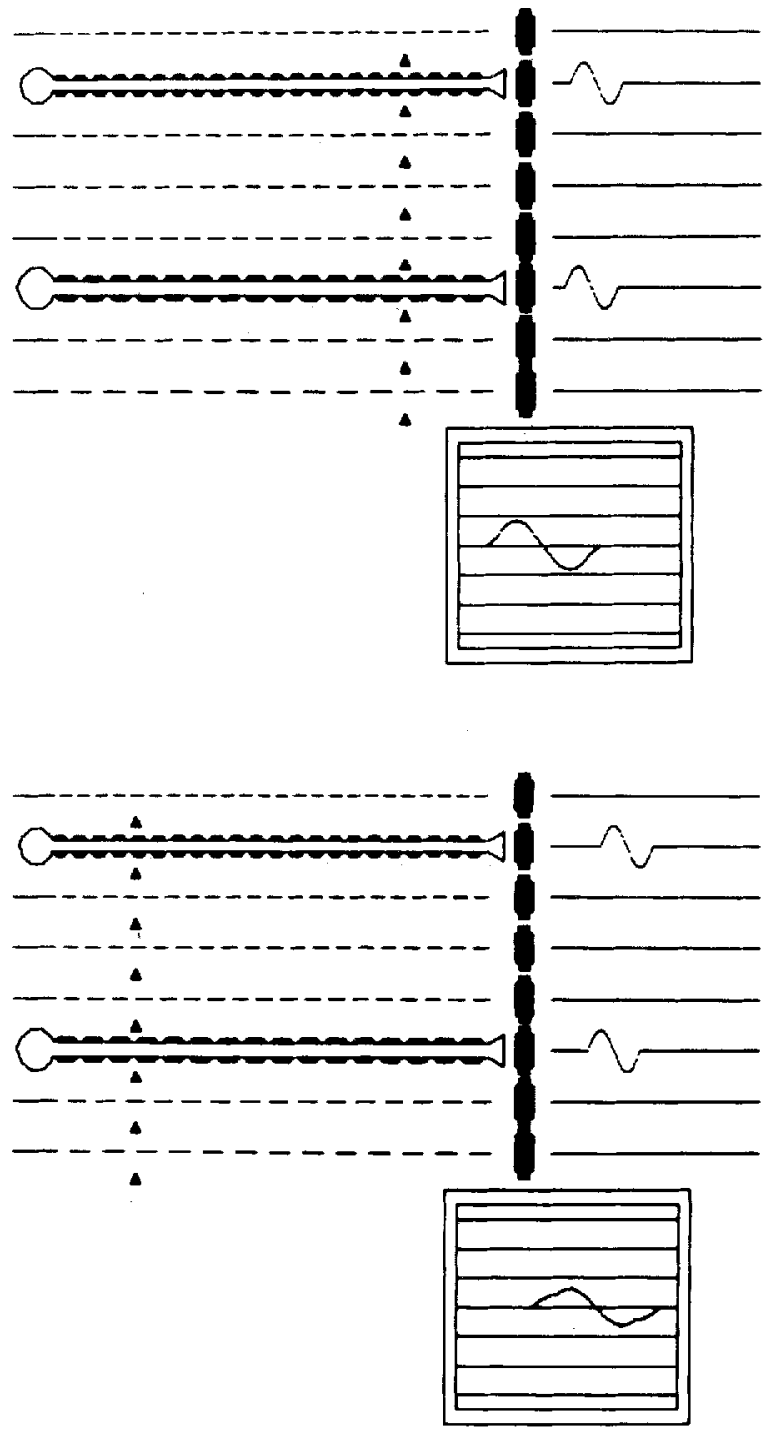

FIGURE 8. Computerized model of axonal degeneration in peripheral motor nerve described in Fig. 7 , following random loss of $75 \%$ of axons. Resultant CMAP after distal (upper screen) and proximal (lower screen) stimulation. Arrows represent stimulation sites. (Reprinted from Ref. 1 with the permission of Butterworths, Copyright 91987 ).

ulation sites. In this model of normal nerve (Fig. 7), the CMAP amplitude can be measured following proximal and distal stimulation. The reduced CMAP amplitude following proximal stimulation reflects the expected temporal dispersion of individual MFAPs and would be increased if either the distance between stimulation sites or the range of conduction velocities were increased.

Following extensive axonal degeneration (Fig. 8), CMAP amplitude diminishes for both proximal and distal stimulation with little change in distal latency or conduction velocity. If the largest axon had remained intact, conduction velocity and dis-
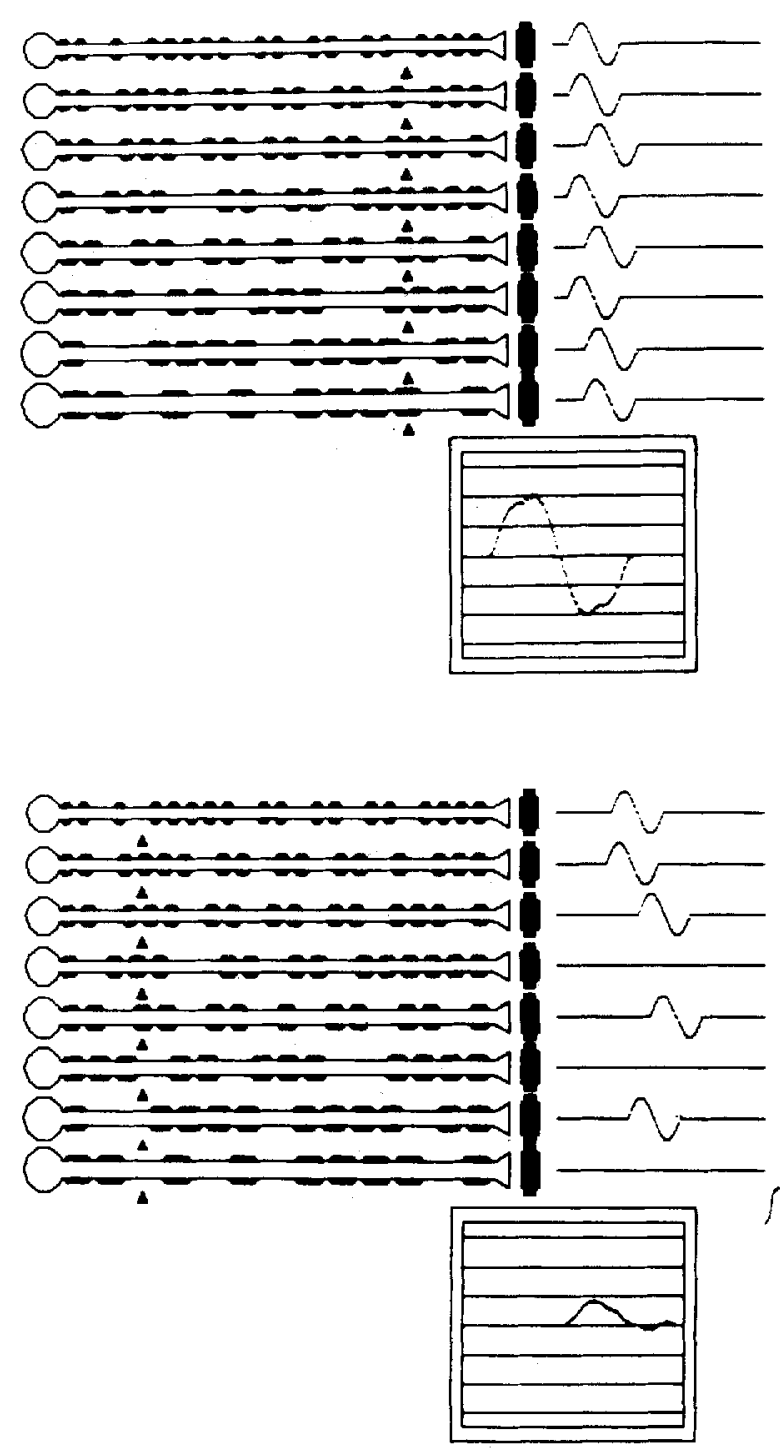

FIGURE 9. Computerized model of multifocal demyelination in peripheral motor nerve described in Fig. 7. Resultant CMAP after distal (upper screen) and proximal (lower screen) stimulation. Arrows represent stimulation sites. The diminished CMAP amplitude with proximal stimulation results from temporal dispersion of individual muscle fiber action potentials and conduction block in some axons. (Reprinted from Ref. 1 with the permission of Butterworths, Copyright (c) 1987.)

tal latency would have been unchanged. The greatest abnormality relative to axonal degeneration would result if only the smallest fiber remained. Both conduction velocity and distal latency would be abnormal, but the magnitude of abnormality would be small compared with the reduced CMAP amplitude.

For comparison, random, multifocal demyelination is demonstrated in Fig. 9. In the model, propagation is slowed across a single demyelinated node, and conduction is blocked if two ad- 
jacent nodes are demyclinated. With distal stimulation, CMAP amplitude is slightly reduced and duration slightly increased because of increased dispersion. Distal latency is slightly prolonged because the largest two fibers are demyelinated distally but the third largest fiber is intact. Proximal stimulation results in pronounced temporal dispersion of the CMAP, explained by the variable amounts of demyclination in some axons compared with the others, producing an increase in the range of conduction velocity. 'This results in the initial component of the CMAP (representing the fastest conduction time) being greatly separated from the trailing portion of the CMAP (representing the slowest conducting axon). The CMAP amplitude with proximal stimulation is reduced to a greater extent than can be explained by temporal dispersion alone, because of conduction block in two of the axons. The likelihood of continuous propagation along the nerve decreases with increasing fiber length because of the increased probability of having demyelination in two adjacent nodes. F response latencies would be increased or unobtainable, depending upon the extent of conduction block. The findings of abnormal temporal dispersion and partial conduction block are very useful in establishing a diagnosis of acute inflammatory polyneuropathy. $\Lambda$ representative recording from a patient early in the course of inflammatory polyneuropathy is shown in Fig. 1 for comparison to the model.

The presence of abnormal temporal dispersion is useful in distinguishing acquired demyelinating neuropathies from hercditary demyelinating ncuropathies. ${ }^{54}$ In the latter, demyelination is uniform and involves all fibers. The range of conduction velocity is not dramatically increased, because all fibers demonstrate conduction slowing to a similar extent. Therefore, conduction velocity may be markedly slowed, but abnormal temporal dispersion does not result.

\section{REFERENCES}

1. Albers JW: Inflammatory demyelinating polyradiculoneuropathy, in Brown WF, Bolton CF (eds): Chinical Electromyography. Boston, Butterworths, 1987, pp 209-244.

2. Albers JW, Donofrio PD, McGonagle TK: Sequential clectrodiagnostic abnormalities in acute inflammatory demyclinating polyradiculoncuropathy. Muscle Nerve 8:528-539, 1985.

3. Albcrs JW, Robertson WC, Daubc JR: Electrodiagnostic findings in acute porphyric neuropathy. Muscle Neree $1: 292-296,1978$

4. Andersonn T, Siden A: A clinical study of the GuillainBarré syndrome. Acta Neurol Scand 66:316-317, 1982.

5. Arnason BGW: Inflammatory polyradiculoneuroparhies, in Dyck PJ, Thomas PK, Iambert EH (eds): Peripheral Neuropathy. Philadelphia, W.B. Saunders, 1975, Vol. 2, pp $110-148$.

6. Asbury AK: Diagnostic considerations in Guillain-Barré syndrome. Ann Neurol 9(Suppl):1-5, 1981.

7. Asbury AK, Arnason BGW, Karp HR, McFarlin DE: Criteria for diagnosis of Guillain-Barré syndromc. Ann Neurol $3: 565-566,1978$.

8. Austin JH: Recurrent polyneuropathies and their corticosteroid treatment. Brain 81:157-194, 1958.

9. Bardwick PA, Zvaifler NJ, Gill GN, Newman D, Greenway GD, Resmick DL: Plasma cell dyscrasia with polyneuropathy, organomegally, endocrinopathy, M-protein and skin changes: the POEMS syndrome. Medicine 59:311--322, 1980 .

10. Baronti F, Sita D: The nosological position of Fisher's syndrome (ophthalmoplegia, ataxia and areflexia). J Neurol 229:33-44, 1983.

11. Bastron JA, Thonas JE: Diabetic polyradiculopathy. Clinjcal and electromyographic findings in 105 patients. Mayo Clin Proc 56:725-732, 1981 .

12. Brown WF, Feasby ' $\Gamma \mathrm{E}$ : Conduction block and denervation in Guillain-Barcé polyneuropathy. Brain 107:219-239, 1984.

13. Campbell Jr WW, Swift TR: Differential diagnosis of acute weakness. South Med J 74:1371-137.5, 1981.
14. Case Records of the Massachusetts General Hospital (Case 32-1984). $N$ Engl J Med 31 1:388-398, 1984.

15. Cooperative French Group: Cooperative randomized trial of plasma cxchange (PE) in Guillain-Barré syndrome (GBS) (abstract). Ann Med Intern 135:8, 1984.

16. Croft $\mathbf{P B}$, Urich $\mathrm{H}$, Wilkinson $\mathrm{M}$ : Peripheral neuropathy of the sensorimotor type associated with malignant disease. Brain 90:31-66, 1967

17. Dalakas MC, Engel WK: Chronic relapsing (dysimmune) polyneuropathy: pathogenesis and treatment. Ann Neurol 9(Suppl): 134-144, 1981 .

18. Daube JR, Kelly JJ, Martin RA: Facial myokymia with polyradiculoneuropathy. Neurology (Minneap) 29:662669,1979

19. Dayan AD, Lewis PD: Demyelinating neuropathy in Waldenstrom's macroglobulinemia. Neurology (Minneap) 16:1114-1144, 1966 .

20. Denys EH, Calanchine PR, Wilson AJ, Brotman M: Chronic demyelinating polyradiculopathy in Hodgkin's disease. Muscle Nerve 6:533, 1983.

21. Donofrio PD, Albers JW, Greenberg HS, Mitchell BS: Peripheral neuropathy in osteosclerotic myeloma: clinical and electrodiagnostic improvement with chemotherapy. Muscle Nerve 7:137-141, 1984.

22. Donofrio PD, Tandan R, Albcrs JW: Plasma exchange in chronic inflammatory demyelinating polyradiculoneuropathy. Muscle Nerve 8:321-327, 1985.

23. Donofrio PD, Wilbourn AJ, Albers JW, Rogers L, Salanga $V$, Greenberg HS: Acute arsenic intoxication presenting as Guillain-Barré syndrome. Muscle Nerve 10:114-120, 1987.

24. Dowling PC, Bosch VV, Cook SD: Possible bencficial effect of high-dose intravenous steroid therapy in acute demyelinating disease and transverse meylitis. Neurology (Minneap) 30:33-36, 1980.

25. Dyck PJ, Daube J, O'Brien P, Pineda A, Low PA, Windebank AJ, Swatson $C$ : Plasma cxchange in chronic polyradiculoneuropathy. N Engl J Med 314:461-465, 1986.

26. Dyck PJ, Lais AC, Ohta M, Bastron JA, Okazaki II, 
Groover RV: Chronic inflammatory polyradiculoneuropathy. Mayo Clin Proc 50:621-637, 1975.

27. Dyck PJ, O'Brien PC, Oviatt KF, Dinapoli RP, Daube JR, Bartleson JD, Mokri B, Swift T, Low PA, Windebank AJ: Prednisone improves chronic inflammatory demyelinating polyradiculoneuropathy more than no treatment. Ann Neurol 11:136-141, 1982 .

28. Dyck PJ, Oviatt KF, Lambert EH: Intensive evaluation of referred unclassified neuropathies yields improved diagnosis. Ann Neurol 10:222-226, 1981.

29. Eisen A, Humphreys P: The Guillain-Barré syndrome. Arch Neurol 30:438-443, 1974.

30. Feasby TE, Hahn AF, Gilbert IJ, Brown WF, Bolton CF, Koopman WJ: Severe acute axonal degeneration in Guillain-Barre syndrome (Abstr.). Neurology (NY) 37(Suppl 1):252-253, 1987.

31. Fisher M: An unusual variant of acute idiopathic polyneuritis (syndrome of ophthalmoplegia, ataxia and areflexia). N Engl J Med 255:57-65, 1956.

32. Greenwood RJ, Newsom-Davis J, Hughes RAC, Aslan S, Bowden AN, Chadwick DW, Gordon NS, McLellan DL, Millar P, Stott RB: Controlled trial of plasma exchange in acute inflammatory polyradiculoneuropathy, Lancet 1:877$879,1984$.

33. Gross MLP, Legg NJ, Lockwood MC, Pallis C: The treatment of inflammatory polyneuropathy by plasma exchange. J Neurol Neurosurg Psychiairy 45:675-679, 1982.

34. Gruener G, Bosch EP, Strauss RG, Klugman M, Kimura J: Prediction of early beneficial response to plasma exchange in Guillain-Barré syndrome. Arch Neurol 44:295-298, 1987.

35. Guiloff RJ: Peripheral nerve conduction in Miller-Fisher syndrome. I Neurol Neurosurg Psychiatry 40:801-807, 1977.

36. Hafler D, Johnson D, Kelly JJ, Panitch H, Kylc R, Weiner HL: Monoclonal gammopathy and ncuropathy: myelin associated glycoprotein reactivity and clinical characteristics. Neurology (NY) 36:75-78, 1986.

37. Hays AP, Iatov N, Takatsu G, Sherman WH: Experimental demyelination of nerve induced by serum of patients with neuropathy and anti-MAG IgM M-protcin. Neurology (NY) 37:242-256, 1987

38. Hockman MS, Kobetz SA, Handwerker JV: Inappropriate secretion of antidiuretic hormone associated with GuillainBarré syndrome. Ann Neurol 1]:322-323, 1982.

39. Hughes RAC, Newsom-Davis JM, Pcrkin GD, Pierce JM: Controlled trial of prednisolone in acute polyneuropathy. Lancet 1:750-753, 1978 .

40. Ilyas AA, Dalakas MC, Brady RO, Quarles RH: Glycolipid antigents in neuropathy associated with monoclonal gammopathy. Neurology (NY) 36(Suppl 1):305, 1986.

41. Inoue A, Tsukada N, Koh CS, Yanagisawa N: Chronic relapsing demyelinating polyneuropathy associated with hepatitis B infection. Neurology (NY) 37:1663-1666, 1987.

42. Keenlyside RA, Schonberger LB, Bregman DJ, Sullivan Bolyai JZ: Fatal Guillain-Barré syndrome after the national influenza immunization program. Neurology. (Minncap) 30:929-933, 1980.

43. Kelly Jr JJ: The electrodiagnostic findings in peripheral neuropathy associated with monoclonal gammopathy. Muscle Nerue 6:504-509, 1983.

44. Kelly Jr JJ: Peripheral neuropathies associated with monoclonal proteins: a clinical review. Muscle Nerve 8:138-150, 1985.

45. Kelly Jr JJ, Kyle RA, Miles JM, Dyck PJ: Osteosclerotic myeloma and peripheral neuropathy. Neurology (NY) 33:202$210,1983$.

46. Kelly Jr JJ, Kyle RA, O'Brien PC, Dyck PJ: Prevalence of monoclonal protein in peripheal neuropathy. Neurology (NY) 31:1480-1483, 1981

47. Kelly Jr JJ, Kyle RA, O'Brien PC, Dyck PJ; The spectrum of peripheral neuropathy in myeloma. Neurology (NY) 31:24-31, 1981 .

48. Kennedy RH, Danielson MA, Mulder DW, Kurland LT: Guillain-Barré syndrome. A 42-year epidemiologic and clinical study. Mayo Clin Proc 53:93-99, 1978.

49. Kyle RA: Monoclonal gammopathy of undetermined significance: natural history in 241 cases. $A m J$ Med 64:814826,1978

50. Kyle RA, Bayrd PR, Banks PM: The diverse picture of gamma heavy chain disease. Mayo Clin Proc 56:499-451, 1981.

51. Lambert EH, Mulder DW: Nerve conduction in the Guillain-Barré syndrome. Bulletin: Am Assoc Electromyogr Electrodiag $10: 13,1963$.

52. Latov N, Sherman WH, Nemni R, Galassi G, Shyong JS, Penn AS, Chess L, Olartc MR, Rowland LP, Osserman EF: Plasma-cell dyscrasia and peripheral neuropathy with a monoclonal antibody to peripheral-nerve myelin. $N$ Engl I Med 303:618-621, 1980.

53. I.evy RI., Newkirk R, Ochoa J: Treating chronic relapsing Guillain-Barré syndrome by plasma exchange. Lancet 2:259-260, 1979 .

54. Lewis RA, Sumner AJ: Electrodiagnostic distinctions betwcen chronic acquired and familial demyelinating neuropathies. Neurology (Minneap) 30:371, 1980.

55. Lewis RA, Sumner AJ, Brown MJ, Asbury MK: Multifocal demyelinating neuropathy with persistent conduction block. Neurology (NY) 32:458-464, 1982

56. Lin JT, Rowe V, Brostoff SW, Abdou NI: Lymphocyte studies in a patient with chronic polyradiculoneuropathy. Neurology (NY) 32:1127-1132, 1982.

57. Lipkin WI, Parry G, Kiprov D, Abrams D: Inflammatory neuropathy in homosexual men with lymphadenopathy. Neurology (NY) 35:1479-1483, 1985.

58. Lippa CF, Chad DA, Smith TW, Kaplan MH, Hammer K: Neuropathy associated with cryoglobulinemia. Muscle Nerve 9:626-631, 1986.

59. Lisak RP, Brown MJ: Acquired demyelinating polyneuropathies. Semin Neurol 7:40-48, 1987.

60. Loeffel NB, Rossi LN, Mumenthaler M, Leutsch J, Iudin HP: The Landry-Guillain-Barré syndrome. Complications, prognosis, and natural history in 123 cases. $J$ Neurol Sci 33:71-79, 1977 .

61. Mark B, Hurwitz BJ, Olanow CW, Fay JW: Plasmapheresis in idiopathic inflammatory polyradiculoneuropathy. $\mathrm{Neu}$ rology (Minneap) 30:361, 1980

62. Martinez-Figueroa A, Hansen S, Ballantyne JP: A quantitative electrophysiological study of acute idiopathic polyneuritis. / Neural Neurosurg Psychiatry 40:156-161, 1977

63. McLeod JG: Electrophysiologic studies in the GuillainBarré syndrome. Ann Neurol 9(Suppl):20-27, 1981.

64. Mcleod JG, Tuck RR, Pollard JD, Cameron J, Walsh JC: Chronic polyneuropathy of undetermined cause. I Neurol Neurosurg Psychiatry 47:530-535, 1984

65. Mendell JR, Kissel JT, Kennedy MS, Sahenk Z, Grinvalsky HT, Pittman GU, Kyler RS, Roelofs RI, Whitaker JN, Bertorini TE: Plasma exchange and prednisone in GuillainBarré syndrome: a controlled randomized trial. Neurology (NY) 35:1551-1555, 1985.

66. Miller RG, Peterson GW, Daube JR, Albers JW: Prognostic value of electrodiagnosis in Guillain-Barré syndrome. Muscle Nerve 11:769-774, 1988.

67. Mishra BS, Sommers W, Koski CL, Greenstein JI: Acute inflammatory demyelinating polyneuropathy in the acquired immune deficiency syndrome (abstract). Ann Neurol $18: 131-132,1985$

68. Mobley WC, Wolinsky JS: Scientific overview of inflammatory demyelinating polyneuropathy and design of the North American Collaborative Study of plasma exchange in Guillain-Barré syndrome, in Tindall RSA (ed): Therapeutic Apheresis and Plasma Perfusion. New York, Alan R. Liss, 1982, pp 159-187. 
69. Murray NMF, Wade D'T: The sural sensory artion potential in Guillain-Barré syndrome (letter). Muste Neree 3:444, 1980.

70. Nakanishi 1', Sobue I, Toyokura Y, Nishitani H, Kuroiwa Y, Satoyoshi F., Tsubaki T, Igata A, Ozaki Y: The CrowFukase syndrome: a study of 102 cases in Japan. Neurolugy (NY) 34:712-720, 1984

71. Osterman PO, Lundemo $G$, Pirskanen R, Fargius J. Pihlstedt. P, Siden A: Beneficial effects of plasma exchange in acute inflammatory polyradiculoneuropathy. Lancet $2: 1296-1313,1984$.

72. Pentland B, Adams GGW, Mawdsley G: Chronic idiopathic polyneuropathy treated with azathioprine. I Neurol Newrosurg Psychiairy 45:866-869, 1982.

73. Peterson GW, Miller RG, Albers JW, Daube JR: Prognoslic valuc of clcctrodiagnosis in Guillain-Barré syndrome (abstract). Muscle Nerue 5:556, 1982.

74. Pleasure DE, Lovelare RE, Duvoisin RC: The prognosis of acule polyradiculoneuritis. Neurology (Minneap) 18:1143$1148,1968$.

75. Posner JB, Ertel NH, Kossman RJ, Scheinberg LC: Hyponatremia in acute polyneuropathy. Arch Newrol 17:539$541,1967$.

76. Prineas J: Polyneutopathies of undetermined cause. Acta Neurol Scand 46:4-72, 1970.

77. Prineas JW, McLeod JG: Chronic relapsing polyneuritis. J Neurol Sci 27:427-458, 1976.

78. Raman PT, Taori GM: Prognostic significance of electrodiagnostic studies in the Guillain-Barre syndrome. I Neurot Neurosurg Psychiatry 25:321-328, 1962.

79. Ravn H: The Landry-Guillain-Barré syndrome: a survey and a clinical report of 127 cases. Acta Nearol Scand 43 (Suppl):427-458, 1967.

80. Ropper AH: The CNS in Guillain-Barré syndrome. Arch Neurol 40:397-398, 1983

81. Ropper $A H$ : Severe acute Guillain-Barré syndrome. Neqrology (NY) 36:429-432, 1986.

82. Ropper AH, Albers JW, Addision R: Limited relapse in GBS after plasma exchange. Arch Neurol 45:314-315, I 988 .

83. Schonberger IB, Hurwitz FS, Katona P, Holman RC, Bregman DJ: Guillain-Barré syndrome: its epidemistogy and associations with influenza vaccination. Ann Neurol 9(Suppl):31-38, 1981 .
84. Server AC, Leftkowith J, Braine H, Mckhann GM: Treatnent of chronic relapsing inflammatory polyradiculoneuroparhy by plasma exchange. Ann Neurol 6:258-260, 1979.

85. Server AC, Stein SA, Braine H. Tandon DS, McKhann GM: Experience with plasma exchange and cyclophosphamide in the treatment of chronic relapsing inflammatory polyradiculoneuropathy. Neurology (Minneap) 30:362, 1980

86. Sherman WH, Latov NH, Hays AP, Takalsu M, Nemni R, Galassi G, Osserman EF: Monoclonal IgMk antibody precipitating with chondroitin sulfate $\mathrm{C}$ from patients with axonal polyneuropathy and epidermolysis. Neurology (NY) $33: 192-201,1983$.

87. Sherman WH, Olatte MR, Mckiernan G, Sweeney K, Latov $N$, Hays AP: Plasma exchange treatment of periphcral neuropathy associated with plasma cell dyscrasia. J Neurol Neurosurg Psychiatry 47:813-819, 1984.

88. Soller D, Feidman S, Alter M: Clinical features of the Guillain-Barré syudrome. J Neurol Sri 37:135-143, 1978.

89. Sumner AJ: The physiological basis for symptons of the Guillain-Barré syndrome. Ann Neurol 9(Suppl):28-30, 1981.

90. The Guillain-Barré Syndrome Study Croup: Plasmapheresis and acute Guillain-Barré syndrome. Neurology (NY) 35:1096-1104, 1985

91. Thomas PK, Lascelles RG, Hallpike JF, Hewert RL: Recurtent and chronic relapsing Guillain-Barré polyneuritis. Brain 92:560-589, 1969.

92. Toyka KV, Augspack R, Wietholter II, Bisinger UA, Haneveld UG, Heininger $\mathbf{K}$, Schwendemann $G$, Reiners $K$, Grabensee B: Plasma exchange in chronic inflammatory polyneuropathy: evidence suggestive of a pathogenic humoral factor. Muscle Nerve 5:479-484, 1982.

93. Tuck RR, McLeod JG: Autonomic dysfunction in GuillainBarré syndrome. J Neurol Neurosurg Psychiairy 44:983-990, 1981.

94. Walker GL: Progressive polyradiculoneuropathy: treatment with azathioprine. Aust NZJ Med 9:184-187, 1979.

95. Wexler 1: Sequence of demyelination-remyelination in Guillain-Barré disease. I Neurol Neurosurg Psychiatry $46: 168-174,1983$.

96. Wiederholt WC, Mulder DW, Lambert EH: The LandryGuillain-Barré-Strohl syndrome or polyradiculoneuropathy: Historical review, report on 97 patients, and present concepts. Mayo Clin Proc 39:427-451, 1964. 